\title{
Traumatic optic neuropathy
}

\section{Eye (2004) 18, 1122-1125. doi:10.1038/sj.eye.6701571}

Keywords: optic nerve; indirect trauma; direct trauma; impairment of vision; head injury; optic nerve injuries

The optic nerve is vulnerable to indirect and direct trauma causing functional impairment of vision. Optic nerve injuries occur in the setting of head injury which is often a consequence of road traffic accidents or falls. The diagnosis of optic nerve injury may be delayed by the presence of other life-threatening injuries. The signs of trauma to the optic nerve are clinical and the examination of acutely injured patients poses difficulties for the clinician. In this article, I shall consider the diagnosis of optic nerve injuries and discuss the dilemmas of management that may arise.

\section{Classification of optic nerve injuries}

Direct injury to the optic nerve should be distinguished from indirect injury. Direct injury arises from penetrating trauma, especially orbital fractures associated with mid-facial fractures. Several varieties of direct optic nerve injury may be recognised ophthalmoscopically or with imaging techniques: optic nerve avulsion, transection, optic nerve sheath haemorrhage, orbital haemorrhage, and orbital emphysema. Indirect optic nerve injury is more common. The force of impact in a head injury may be transmitted to the optic nerve. This complication of head injury was known to Hippocrates who noted that blows to the eyebrow may cause blindness. The frequency of optic nerve injury occurring in closed head injury varies from 0.5 to $5 \% .{ }^{1}$ The site of injury causing blindness is usually the forehead or supraorbital ridge, less commonly the temporal region. Generally, the blow is severe causing loss of consciousness, but occasionally the trauma may be slight and the patient only slightly dazed. The clinical sequence of events is typical; the patient recovers consciousness after head injury and discovers that the sight of one eye is damaged or lost. Ocular examination is initially normal apart from a relative or absolute afferent pupillary defect. A wide variety of visual field defects may occur. Optic atrophy develops after 4-6 weeks.

\section{Direct optic nerve injury}

There are distinctive clinical syndromes of direct optic nerve injury that may be recognised by clinical examination and neuro-imaging using CT or MRI scanning ${ }^{2}$ (Figures 1 and 2).

Optic nerve avulsion usually follows severe orbital trauma, but cases have been reported following relatively trivial injury. Vision loss is usually severe and immediate.

Ophthalmoscopy shows absence of the optic disc and a ring of haemorrhage. Imaging may confirm the diagnosis but may show an intact sheath. Ultrasound may be helpful. ${ }^{3}$ The nerve tears at the lamina cribrosa, perhaps as a result of rotation of the globe, raised intraocular pressure or sudden retropulsion followed by anterior displacement. No treatment is possible.

Optic nerve transection occurs as a complication of midfacial trauma and orbital fracture. There is no light perception, corroborated by visual evoked potentials. CT scanning may show the bone fragment transecting the optic nerve. No treatment is effective.

Optic nerve sheath haemorrhage may be difficult to recognise clinically and yet cause potentially reversible visual failure. An expanded nerve sheath associated with proptosis should raise the possibility of a haematoma in the optic nerve sheath, which can be drained via a sheath fenestration.

Orbital haemorrhage may be diffuse or localised to the orbit. There is an associated proptosis and ophthalmoplegia. The injury to optic nerve function results from raised pressure in the orbit and may be relieved by elevating the head and administering Diamox to lower the intraocular pressure. If conservative measures fail, then a lateral canthotomy and
2003

Accepted: 4 September 2003 


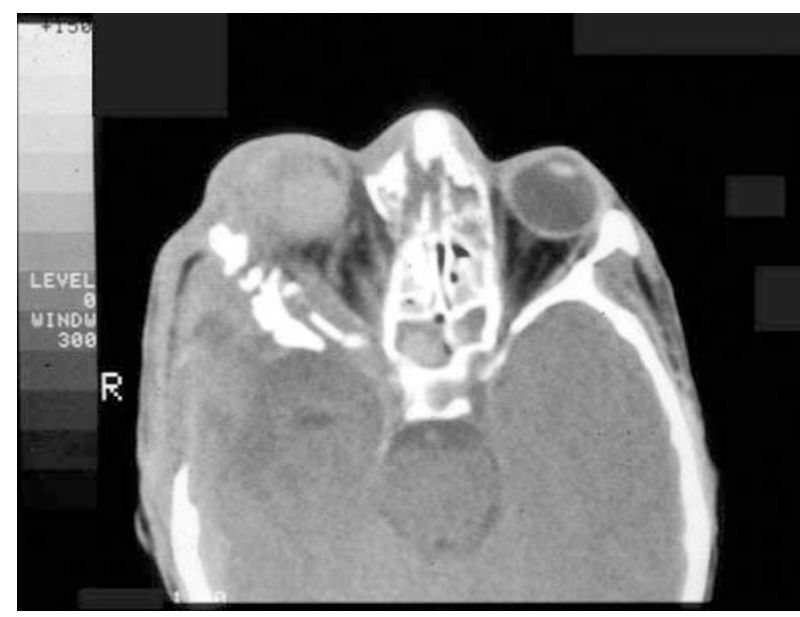

Figure 1 CT scan of orbit showing disrupted optic nerve following penetrating trauma (Sarkies ${ }^{2}$ ). Reprinted with permission from Elsevier.

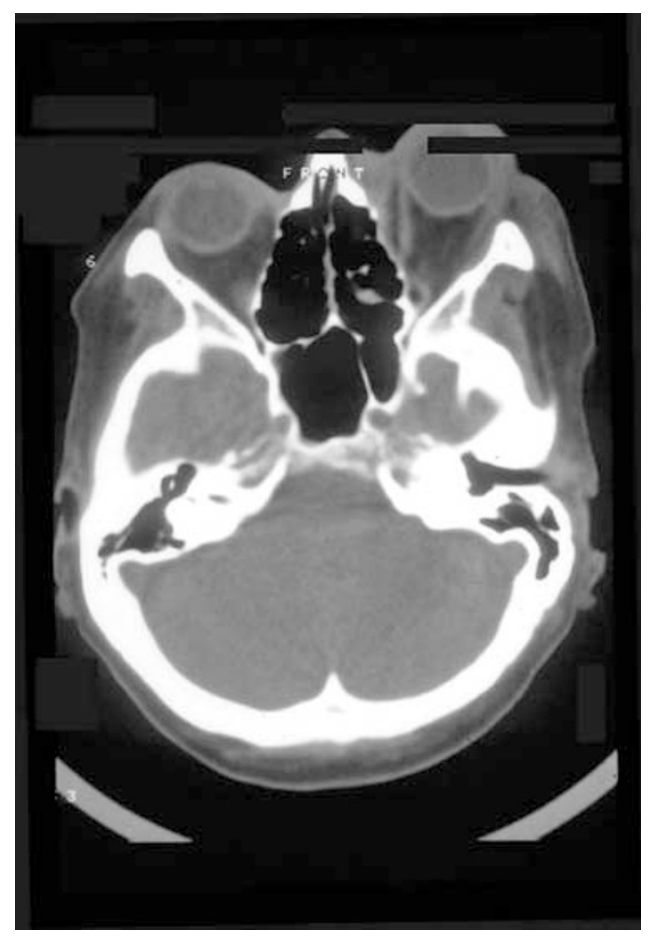

Figure 2 CT scan of orbit showing proptosis and distension of optic nerve sheath with probable haematoma (Sarkies²). Reprinted with permission from Elsevier.

drainage of orbital haemorrhage may restore function.

Orbital emphysema is a well-recognised clinical entity in the setting of injury to the paranasal sinuses. Hair-line fractures of the thin bone lining the orbital walls may produce a ball-valve effect so that air accumulates in the orbit and causes proptosis and compression of the eye and nerve. Drainage of the air by a retrobulbar needle has been effective.

\section{Indirect optic nerve injury}

The mechanism of damage to the optic nerve by closed head injury has been extensively studied. After blunt trauma to the superior orbital rim or fronto-temporal region of the cranium, compression forces are transmitted to the orbital apex and optic canal. ${ }^{4}$ Within the canal, the optic nerve dura fuses with the periosteum of the bone. Since the vasculature of the optic nerve in the canal is pial, compression and contusion of the nerve produce a compartment syndrome whereby swelling exacerbates the ischaemia. ${ }^{5}$ The optic nerve is also vulnerable to a shearing injury under the fixed edge of the falciform dural fold just before it enters the optic canal. Histopathological studies by Crompton ${ }^{6}$ of 174 patients who died after closed head injury found evidence for haemorrhage in the optic nerve sheath $(83 \%)$, in the nerve interstitium (36\%), and shearing lesions and ischaemic necrosis of the intracanalicular and intracranial segments of the nerve.

\section{Treatment of indirect optic nerve injury}

The management of indirect optic nerve injury is controversial. There may be delay in diagnosis, and occasionally the loss of visual function appears as a delayed complication of head injury. The arguments for treatment of indirect optic nerve injuries are based upon the hypothesis that secondary injury to the axons occurs as a result of vasospasm and swelling within the optic canal. Experimental studies of optic nerve injury have employed crush, stretch, or severing injuries. The cellular mechanisms involved in CNS injury are incompletely understood. To summarize, several cellular messengers are activated by the trauma response. The release of oxygen-free radicals results in peroxidation of lipid cell membranes. Bradykinin and kallidin are activated following injury: these agents influence free radical production, intracellular calcium production, and arachidonic acid release from neurons. Subsequently cellmediated inflammation certainly plays a prominent part in experimental models of optic nerve injury.

Very high-dose corticosteroids limit free-radical amplification of the injury response. The use of high-dose corticosteroids after optic nerve injury increased in the $1980 \mathrm{~s}$ following the report of Anderson et al. ${ }^{4}$ The rationale was strengthened by studies on spinal cord injury. The second National Acute Spinal Cord Injury Study (NASCIS 2) was a multicentre, randomised, double-blind, placebo-controlled study of patients with acute spinal cord injury. ${ }^{7}$ Patients were treated with 
placebo, naloxone, or methylprednisolone, administered with an initial dose of $30 \mathrm{mg} / \mathrm{kg}$ followed by an infusion at $5.4 \mathrm{mg} / \mathrm{kg} / \mathrm{h}$ for $24 \mathrm{~h}$. Patients were evaluated by pinprick, light touch, and motor function initially, then at 6 weeks and 6 months. The study showed that the treatment with methylprednisolone within $8 \mathrm{~h}$ of injury resulted in a significant improvement in motor and sensory function compared to placebo-treated patients. Further analysis of the data suggested that methylprednisolone treatment initiated more than $8 \mathrm{~h}$ after spinal cord injury may be detrimental. ${ }^{8}$ NASCIS 3 established that treatment should be continued for $24 \mathrm{~h}$ if initiated within $3 \mathrm{~h}$ after injury, but for $48 \mathrm{~h}$ if initiated within 3-8 $\mathrm{h}^{9}$

Surgery to decompress the optic canal, via intracranial, transethmoidal, endonasal, even sublabial approaches has been advocated in many retrospective reports. ${ }^{10-13}$ The reports of outcome after surgery are subject to several limitations: there is a tendency to operate on patients with no light perception, some case series include patients with direct optic nerve injury, many patients are also treated with steroids in high dosage, and there is an inherent difficulty defining improvement when the first assessment is made at the bedside and the final assessment in the clinic. Retrospective reports of the use of high-dose steroids are also subject to similar criticisms. $^{14-16}$

The natural history of traumatic optic neuropathy has not been studied prospectively, but several authors have reported that spontaneous recovery may occur in at least a third of patients. ${ }^{17-19}$ There has been no randomised, placebo-controlled study of patients with indirect optic nerve injury. A study of current practice in 16 countries was carried out between 1994 and 1997. ${ }^{20} \mathrm{~A}$ total of 133 patients (127 unilateral, six bilateral) who were initially assessed within 3 days of the optic nerve injury were treated with corticosteroids, optic canal decompression surgery, or observed without treatment. At least 1 month of follow-up was required for inclusion. Nine patients were untreated, 85 treated with corticosteroids, and 33 with decompression surgery. Visual acuity increased by 3 or more lines in $32 \%$ of the surgery group, $57 \%$ of the untreated group, and $52 \%$ of the steroid group. More patients whose initial vision was no light perception were treated with surgery. After adjustment for the initial vision, there were no significant differences between any of the treatment groups. There was no indication that the dose or timing of corticosteroid treatment or the timing of surgery was associated with an increased probability of visual improvement. The number of patients studied was sufficient to detect major differences between the treatment groups. Therefore, this study has not defined a standard protocol of treatment for indirect optic nerve injury.
High-dose steroids may have serious side effects; optic nerve decompression surgery may entail further complications as a result of damage to neighbouring structures in the orbit and region of the sella. In view of the uncertainties about the value of intervention, particularly after $8 \mathrm{~h}$, specific treatment may not be indicated for many patients with indirect optic nerve injury. It is doubtful that a randomised controlled clinical trial of the use of high-dose steroids or decompression surgery will be undertaken in this condition. Measures to avoid injury and research to establish better neuroprotective strategies offer the best hope of progress in the future.

\section{References}

1 Steinsapir KD, Goldberg RA. Traumatic optic neuropathy. Surv Ophthalmol 1994; 38(6): 487-518.

2 Sarkies NJC. Neuro-ophthalmological aspects of head injury. In: Macfarlane R and Hardy D (eds) Outcome after Head Neck and Spinal Trauma. Butterworth Heinemann: Oxford, 1977 pp 163-177.

3 Sawhney R, Kochhar S, Gupta R, Jain R, Sood S. Traumatic optic nerve avulsion: role of ultrasonography. Eye 2003; 17: 667-670.

4 Anderson RL, Panje WR, Gross CE. Optic nerve blindness following blunt forehead trauma. Ophthalmology 1982; 89: 445-455.

5 Walsh FB, Hoyt WF. Clinical Neuro-ophthalmology, 3rd ed. Williams and Wilkins: Baltimore, 1969 p 2380.

6 Crompton MR. Visual lesions in closed head injury. Brain 1970; 93: 785-792.

7 Bracken MB, Shepard MJ, Collins WF, Holford TR, Young $\mathrm{W}$, Baskin DS. A randomized, controlled trial of methylprednisolone or naloxone in the treatment of acute spinal-cord injury. Results of the Second National Acute Spincal Cord Injury Study. N Engl J Med 1990; 322: 1405-1411.

8 Bracken MB, Holford TR. Effects of timing of methylprednisolone or naloxone administration on recovery of segmental and long-tract neurologic function NASCIS 2. J Neurosurg 1993; 79: 500-507.

9 Bracken MB, Shephard MJ, Holford TR, Leo-Summers L, Aldrich EF, Fazl M. Administration of methylprednisolone for 24 or 48 hours or tirilazad in the treatment of acute spinal cord injury. Results of the third national acute spinal cord injury randomized trial. JAMA 1997; 277: 1597-1604.

10 Fukado Y. Results in 400 cases of surgical decompression in the optic nerve. Mod Prob Ophthalmol 1975; 14: 474-481.

11 Fujitani T, Inoue K, Takahashi T et al. Indirect traumatic optic neuropathy - visual outcome of operative and nonoperative cases. Jpn J Ophth 1986; 30: 125-134.

12 Levin LA, Joseph MP, Rizzo JF, Lessell S. Optic canal decompression in indirect optic nerve trauma. Ophthalmology 1994; 101: 566-569.

13 Chou PI, Sadun AA, Chen YC. Clinical experiences in the management of traumatic optic neuropathy. Neuroophthalmology 1996; 16: 325-336.

14 Spoor TC, Hartel WC, Lensink DB, Wilkinson MJ. Treatment of optic neuropathy woith corticosteroids. Am J Ophthalmol 1990; 110: 665-669. 
15 Seiff SR. High dose corticosteroids for treatment of vision loss due to indirect injury to the optic nerve. Ophthalmic Surg 1990; 21: 389-395.

16 Mauriello JA, DeLuca J, Krieger A et al. Management of traumatic optic neuropathy - a study of 23 patients. $\mathrm{Br} \mathrm{J}$ Ophthalmol 1992; 76: 349-352.

17 Turner JWA. Indirect injuries of the optic nerve. Brain 1943; 66: $140-151$.
18 Hooper RS. Orbital complications of head injury. Br J Surg 1951; 39: 126-138.

19 Wolin MJ, Lavin PJM. Spontaneous visual recovery from traumatic optic neuropathy after blunt head injury. Am J Ophthalmol 1990; 109: 430-435.

20 Levin LA, Beck RW, Joseph MP et al. The treatment of traumatic optic neuropathy: the International Optic Nerve Trauma Study. Ophthalmology 1999; 106(7): 1268-1277. 